\title{
REVIEWS
}

TREATMENT OF SHOCK

Medical Research Council. War Memorandum No. 1: The Treatment of "Wound Shock.

(H.M. Stationery Office, London. 1944. 2nd Ed. Pp. 32. 6d.)

A number of different conditions due to different sorts of trauma are comprised in the term 'shock,' and throughout the memorandum, now in its second edition, the indefinite connotation of the term is emphasized by the use of inverted commas.

Severe limb wounds and burns bulk large among causes of 'shock' and, since their initial mortality is lower than, for example, severe visceral injuries, they have provided the material for most of the investigations of 'shock.' In 'shock' due to limb wounds and burns oligaemia, due to loss of blood or plasma externally or into the traumatized area, is regarded as the most important etiological factor. Loss of blood, if amounting to 25 per cent. or more of the total blood volume, can produce signs of 'shock'; low blood pressure; poor, rapid, pulse; pallor or cyanosis, and sweating; and vomiting. Similar symptoms may follow the loss of smaller quantities of blood in susceptible people, and if the blood loss is accompanied by pain or occurs when the subject is in an upright position vaso-vagal collapse ensues. It is also to be noted that a low blood-pressure is not invariable, and the severity and nature of the injury may often be a better guide to the diagnosis of "shock and to the need for transfusion than the blood-pressure. Haemoglobin estimations in the early hours of "shock due to haemorrhage are of no value as an index of blood loss since the restitution of the blood volume by dilution with tissue fluid takes some hours.

In burns it is thought that the 'shock' is due to increased capillary permeability in and around the burn leading to transudation of plasma and to haemoconcentration; haemoglobin estimations are therefore of value in assessing the degree of 'shock' in burns. In injuries involving the crushing of large amounts of muscle, 'shock may follow the release into the circulation of the diffusible constituents of necrotic muscle, and in such cases there is frequently renal failure. Other complications of wounding that may lead to symptoms of " shock " include fat embolism, inhalation of toxic gases, infection, anaesthesia, and dehydration.

In the treatment of the "shocked' patient there are three main aims: arrest of haemorrhage, restoration of blood volume, and removal of damaged tissue. The operation should be carried out as soon as possible and resuscitation measures may often be best carried out in the operating theatre immediately prior to surgical treatment. Haemorrhage is most satisfactorily controlled by local pressure dressings; the injured part should be well immobilized. Morphine, $\frac{1}{6}$ grain intravenously, may be given to relieve apprehension. Copious drinks should be given. Transfusion is the only measure that will save life in the severely 'shocked 'patient. If the systolic blood pressure is below 90 and the pulse is rapid, transfusion should not be delayed. In other cases the decision may be more difficult, but it is better to give than to $\mathrm{withhold}$ transfusion, and the presence of a large mass of injured tissue in a limb, even though the blood pressure is normal, is often a definite indication for transfusion. Blood is the transfusion fluid of choice when the 'shock' is due to blood loss: plasma or serum should be used for patients with haemoconcentration.

In both limb injuries and burns a transfusion may be enough to bring the patient out of 'shock' and yet leave him very liable to relapse later, e.g. at operation. Adequate amounts of fluid should therefore be given.
The transfusion of too much fluid, however, may lead to pulmonary oedema, as may transfusion in patients with trauma to the lung-thermal or toxic. Oxygen is only indicated in patients with pulmonary oedema or some interference with respiratory oxygen intake.

R. E. O. W.

\section{HEALTH RESEARCH IN INDUSTRY}

Proceedings of a Conference on Industrial Health Research held at the London School of Hygiene on September 28th, 1944.

(H.M. Stationery Office, London. 1945. Pp. 27. 6d.)

It cannot be denied that between the wars industrial health research failed to attract the interest it deserved. It was neglected by industrialists and Trades Unions alike and so was denied the place it should have held in an industrial community. In 1942, however, the Industrial Health Research Board was reconstructed and its terms of reference revised; the result has been a welcome change in attitude. The Board now accepts the view that it must serve industry, and that to do so it must keep in close contact with it. So a conference was convened by the Board and was a highly successful attempt to bring employers and Trades Union officials into its councils.

The report of the conference is of much interest. A stimulating account of the work of the Department for Research in Industrial Medicine at the London Hospital is given by Dr. Donald Hunter: he illustrates the part to be played by similar departments in the prevention of illness resulting from the exposure of the worker to toxic hazards. Lord Forrester speaks for employers, and deals with some of the more general health problems of industry. He touches on posture, on sickness records and on working time. It is important to look further than the hours per week; we must think rather in terms of hours per year. More attention should be paid to the location of industry; this he regards as within the province of industrial health research. He lays great stress on the need for dissemination of information on health matters to workers and management alike, but this must be presented in an effective and readable form. The point of view of the Trades Unions is given by Mr. Isaacs; and if undue stress appears to be laid on the prevention of industrial diseases it must be remembered that the attitude of the Trades Unions has been determined by their long fight to have certain of these diseases included in the schedule of the Workmen's Compensation Act. Mr. Isaacs, however, does not by any means confine himself to the narrower issue, but develops the thesis that research into problems of industrial health can pave the way to some of those freedoms expounded in the Atlantic Charter. Dr. Craik, Director of the Unit for Applied Psychology at Cambridge, briefly outlines the post-war programme of his department, and shows the need for confirming the consistency and validity of the tests which have been evolved for allocating the man to the job. The importance of the application of the results of research to industrial practice is rightly stressed by the Secretary of the Medical Research Council, Sir Edward Mellanby. He says that 'research work can only be a spearhead, and a spearhead without a shaft and without some one to hurl it is no good whatever'. He goes on to say that 'it is up to employers and to the Trades Unions to play their part and to see that these spearheads are not allowed to lie about as litter, but are fashioned into effective implements and so hurled as to do their job and maintain industry at the highest level of efficiency and to provide us with healthy and contented workers'. R. E. L. 